\title{
EL CANTO DE LA ALONDRA. ESTUDIOS SOBRE MARÍA ZAMBRANO
}

\author{
Armando LÓPEZ CASTRO
}

(Universidad de León: Área de Publicaciones, 2013, 220 págs.)

Escribir supone un reto con uno mismo, con su ser y con sus circunstancias, pues "escribir es enfrentarse a una realidad desconocida, que nos desborda e impone su ritmo", como afirma el profesor Armando López Castro en su libro El canto de la alondra. Estudios sobre María Zambrano (2013). Estamos ante una completísima obra llena de hondas reflexiones y con una cuidada expresión que destaca por el empleo de frases cargadas de lirismo y de un profundo significado o de una trascendencia que supera los límites de la palabra misma. La obra es un estudio acerca de la trayectoria literaria de la escritora malagueña enriquecido con apuntes, referencias, reflexiones e ideas de numerosas personalidades de la literatura, de la pintura o de la filosofía como Unamuno, Machado, Cernuda, Ortega y Gasset, Galdós, Teresa de Jesús, Juan de la Cruz, Cervantes, Valente, Picasso, Miró, Goya, Kandinsky, Rousseau, Freud, Jung, Heidegger, Pascal, Novalis, Nietzsche, Platón, Heráclito, Walter Benjamin, etc.

Por otro lado, el título del libro nos hace recordar un artículo de José Luis Abellán, titulado precisamente "María Zambrano, alondra de la filosofía", recogido en el volumen María Zambrano: la visión más transparente (2004), en el que ya se revelaban muchas de las claves que influyeron en la escritura de Zambrano y que López Castro analiza en profundidad a lo largo de su estudio, con un interés primordial por la música, y que desvelan 
que la escritura en Zambrano renace en cada palabra o pensamiento recogidos en lo más profundo del ser, en el alma misma, pues, según Abellán:

Ese vuelo del alma, que es palabra indecible, asimilada al canto y a la música es la expresión más plena de lo que constituye el pensamiento filosófico de María Zambrano, equiparable en esto al canto de la alondra". [... ] es sabido que la alondra tiene la virtud de elevarse rauda hacia el cielo y de dejarse caer también bruscamente en la tierra, y esos dos vuelos - de la tierra al cielo, y viceversa- han hecho que los mitólogos vean en ella un símbolo de los dos polos de la existencia en sus expresiones opuestas. [...] En la alondra - de vuelo muy alto, de cuerpo escueto y de gran velocidad en su elevación - han visto los estudiosos de la simbología, una metáfora pura —expresión de transparencia del gozo-; de aquí que Bachelard la llame 'vertical del canto'. En esa vertical del canto encontramos nosotros el simbolismo específico que ilumina el sentido más profundo de la filósofa malagueña. La filosofía de María Zamorano - alondra ella misma - es un saludo a la primavera de un nuevo amanecer - filosófico y femenino, al mismo tiempo- en vuelo hacia la aurora anunciada (Abellán, J. L. "María Zambrano, alondra de la filosofía". En María Zambrano: Ia visión más transparente, Juan Antonio González Fuentes y José María Beneyto Pérez (coords.), 311-318. Madrid: Trotta Editorial, 2014l).

Tras el prólogo inicial titulado "La aventura del escribir" vienen doce capítulos de desigual extensión en los que se profundiza en las señas de identidad de la escritura de María Zambrano. El primero de los capítulos, "María Zambrano: ánima hispánica”, intenta demostrar cómo influyeron en sus escritos ciertos hechos históricos acaecidos en España, pues precisamente "los momentos verdaderamente históricos son aquellos que dejan ver transparentes sus entrañas: las de la historia y las del hombre que la protagoniza". María Zambrano vivió la Il República, la Guerra Civil y luego el exilio, momentos históricos decisivos que marcaron su vida y su escritura. De esta manera, en el capítulo tercero del libro donde trata la experiencia del exilio, López Castro afirma que, según la autora, "el exilio hay que merecerlo. Desde este punto de vista, el exilio es una condición más mental que material, que uno escoge libremente y tiene que hacerse digno de él". Para Zambrano, a diferencia de Unamuno o Machado, el exilio "fue un logro, no una pérdida, que le permitió un desarrollo propio", logrando que su escritura y su exilio recorrieran un mismo camino y se enriquecieran mutuamente, dando lugar a su peculiar concepción de la razón poética, como se estudia a lo largo del segundo de los capítulos, una razón poética que ha de entenderse como "memoria desposeída de identidad" y como "modo de conocimiento desligado de lo racional y unido a lo espontáneo".

En los siguientes siete capítulos, el profesor López Castro indaga acerca de la importancia y tratamiento de lo sagrado, de la música, del realismo, de la pintura, del sueño, de la tradición mística y de la ausencia del amor en los escritos de María Zambrano. Así, lo sagrado resulta un término que es necesario recuperar, "pues el no contar con los dioses le impide al hombre seguir viviendo" ya que "la verdadera realidad siempre está en aquello que no tenemos, en ese más allá que pertenece al ámbito irreductible de lo sagrado, y tal vez por ello resulta tan difícil que se revele". Asimismo, para Zambrano "la experiencia erótica y la experiencia mística forman parte de una misma experiencia religiosa, donde convergen y desde la que sólo pueden ser entendidas". Relacionado con lo sagrado y con la experiencia religiosa, la conexión entre música y poesía se entiende como "viaje iniciático al 
interior del alma", de la misma manera que "la función de la pintura, que es revelación de un misterio siempre inacabado, consistirá en liberar los fantasmas, los cuerpos impalpables de los sueños, que aparecen incompletos, con zonas oscuras [...]". Junto con la música y la pintura, el sueño, la experiencia onírica y la revelación de aquello que se sueña a través de la palabra, "sustancia última de la poesía, equivale a instalarse en el centro germinante de la experiencia onírica, donde se despierta el deseo de restituir las formas originarias". De esta manera, según Armando López, el sueño "nos abre a lo desconocido, a un nuevo saber posible, en un viaje a los límites del ser". El tiempo del sueño, por lo tanto, "se presenta como proyección de lo íntimo, como un proceso de algo que está por hacer, de manera que ese tiempo sin memoria [...] nos lleva a conjurar la plenitud, a reconocer la unidad en los límites de la diferencia". Así se observaría, por ejemplo, en sus obras El sueño creador (1965), Claros del bosque (1977) o en su obra póstuma Los sueños y el tiempo (1992).

Por otro lado, en relación con cómo entendió Zambrano el realismo hay que tener en cuenta, según López Castro, que su peculiar entendimiento y su personal vivencia de la tradición española suscitó que la escritora se insertara en esa tradición de manera dinámica "para seguir un hilo conductor no sujeto a corrientes o escuelas, lo cual le ha permitido poner al alcance del lector nuevas formas de interpretación" y nuevas maneras de tratar temas tan universales como el amor que para Zambrano "sólo vive renaciendo sin cesar" donde "la búsqueda del amor participa de una doble posesión, consistente en poseer lo que nos posee" ya que "lo que se experimenta con el amor es el conocimiento de aquello que es desconocido. Y lo que mejor caracteriza al enamoramiento es la conversión"; ese convertirse en otro ser distinto, como haría el emparejamiento entre el amor y la poesía mismos, donde la palabra resurge sin cesar y donde "nace el amor en la ausencia del otro, y desde ella, aspira a la unidad, a la reducción de las tensiones, siendo esa distancia de lo incierto el riesgo que el enamorado debe correr". De ahí que el profesor López Castro hable de "La ausencia del amor en María Zambrano", un amor renovado ante la ausencia de lo que se ama en relación también con la alta estima que Zambrano tenía a la filosofía, entendida como una forma de amor y como expresión del amor mismo.

El capítulo nueve, titulado "Hacia una poética del fragmento en María Zambrano", indaga acerca de cómo entendió la autora la escritura fragmentada como vía para explorar lo desconocido "que es el territorio de lo indeterminado, cuya incierta presencia es la que da origen a la escritura poética", rompiendo la homogeneidad, intensificando el tono elegíaco de cierta realidad o mostrando "la violencia de lo sistemático [tendiendo] por eso a instalarse en lo que todavía no ha sido dicho, de ahí su carácter de pura inmanencia, a ser el lugar de la palabra naciente".

El último capítulo, "María Zambrano y José Ángel Valente", estudia la relación que existió entre los dos escritores caracterizada por la admiración del poeta hacia Zambrano, nacida en un primer momento de la simple e inocente curiosidad, la complicidad por compartir ciertos pensamientos y/o experiencias y el distanciamiento necesario y propio de aquel que de aprendiz pasa a querer expresarse por cuenta propia. Armando López nos cuenta que ambos escritores se conocieron en julio de 1964, momento desde el cual Valente siempre valoró "la plenitud de esta pensadora", influyendo en sus propias composiciones y en su manera de concebir la poesía ya que su inmanencia mantiene una estrecha relación con la teoría de la razón poética de Zambrano.

El libro finaliza con un epílogo en el que la palabra se revela como germinadora o principio de la creación o en palabras de la propia escritora: "La palabra ha sido en mí, desde 
el principio, en mi pensamiento y en mi alma, eso justamente, el principio, como dice el Evangelio de San Juan: el principio era el Verbo y el Verbo era la Luz y la Luz era la Vida y el Verbo se hizo carne y habitó entre nosotros lleno de gracia y de verdad. Esta es la revelación que me ha sostenido a lo largo y ancho de toda mi vida".

El poder de las palabras se postula como origen de todos los actos llevados a cabo por los seres humanos y la sabiduría o el conocimiento que se logra a través de ellas se hacen necesarios para la consecución de una vida más plena merecedora de ser contada, de ser vivida, en definitiva, pues "saber nos proporciona experiencia, un conocimiento de la vida en su integridad. Y la plenitud de lo vivido, a la que no debemos renunciar, se da en la madurez, que se levanta contra la destrucción de la memoria y la palabra".

Nuria Sánchez Villadangos

Universidad de León 